\title{
«NUESTRO PUESTO ESTÁ EN EL HOGAR». LOS CAMPAMENTOS FEMENINOS EN ASTURIAS DURANTE EL PRIMER FRANQUISMO (1938-1945)
}

\author{
"Our Place Is at Home». Female Summer Camps in Asturias during the First Years \\ of Francoism (1938-1945)
}

\author{
Mónica García Fernández \\ Universidad de Oviedo \\ garciafmonica@gmail.com
}

Fecha de recepción: 29-II-2012

Fecha de aceptación: 10-IV-2012

RESUMEN: Una de las iniciativas más populares y anunciadas destinadas a las juventudes durante el Franquismo fueron los campamentos y albergues de verano. En ellos se trataba de construir una sociedad ideal y armónica a pequeña escala, sin clases ni nacionalismos periféricos y en la que funcionaran perfectamente los roles de género impuestos por el Estado franquista. En este artículo me centraré en analizar el discurso oficial y las actividades dirigidas a las niñas y jóvenes en estos campamentos, que estaban especialmente concebidos para orientarlas hacia su destino social: la maternidad y el cuidado del hogar. Para ello tomaré como ejemplo los organizados en Asturias entre 1938 y 1945. Las fuentes utilizadas son fundamentalmente hemerográficas, provenientes de los diarios falangistas asturianos La Nueva España y Voluntad, aunque también haré referencia a algunos documentos del Fondo de la Delegación Provincial de la Sección Femenina conservados en el Archivo Histórico de Asturias.

Palabras clave: Franquismo, Sección Femenina, Frente de Juventudes, Asturias, género, juventudes femeninas, campamentos.

Aвstract: One of the most popular and advertised initiatives aimed at young people and children during the Francoist period were the summer camps. They tried to build an ideal society there, with no social classes or nationalisms and with a perfect performance of the gender roles imposed by the Francoist authorities. In this paper I will focus on the official speech and activities addressed to female children and young women in these 
summer camps, which were specially designed to familiarise them with their future social roles: motherhood and housekeeping. To do so, I will use as an example the ones located in Asturias between 1938 and 1945.

Keywords: Francoism, Feminine Section, Asturias, gender, young women, summer camps.

\section{INTRODUCCIÓN}

«Nuestro puesto está al aire libre». Ésta fue una de las consignas utilizadas para anunciar y glorificar los campamentos estivales de las Organizaciones Juveniles de Falange (Frente de Juventudes desde diciembre de 1940) ${ }^{1}$, una de las iniciativas más populares destinadas a los y las militantes menores de edad $^{2}$. El pegadizo eslogan resumía el entusiasmo con el que se veían las prácticas realizadas en el exterior como fuente de salud, vigor y fortaleza. No obstante, aunque es posible que esta imagen tan enérgica y vital que nos ofrece la expresión pueda parecernos masculina, ciñéndonos a los extendidos estereotipos que vinculaban a las mujeres al interior del hogar, en realidad también se aplicó al caso femenino.

\section{Los hombres -las mujeres- hemos de crecer a los cuatro vientos para} fortificar nuestro organismo. Y si en verdad somos flores, debemos ser flores al

1 La expresión fue utilizada para anunciar la campaña de campamentos del verano de 1942 y estaba tomada directamente del famoso discurso pronunciado por José Antonio Primo de Rivera en el Teatro de la Comedia de Madrid el 29 de octubre de 1933. La frase completa decía lo siguiente: «Nuestro puesto está al aire libre, bajo la noche clara, arma al brazo, y en lo alto, las estrellas». Estas palabras hacían referencia al carácter revolucionario del falangismo, que no esperaba llegar al poder por medios pacíficos. Las connotaciones masculinas de este mensaje son evidentes y, como es conocido, las mujeres fueron excluidas del movimiento precisamente por esa violencia que se preveía. Por ello, un pequeño grupo de ellas decidió formar la Sección Femenina, que se encargaría de actividades subalternas y de apoyo, aunque no por ello exentas de riesgo. Para más información sobre el origen y evolución de la organización véase Gallego Méndez (1983), Richmond (2004) o Sánchez López (2007).

2 Hasta 1945 las niñas estuvieron integradas en las Organizaciones Juveniles primero y en el Frente de Juventudes después, para pasar entonces a depender exclusivamente de la Sección Femenina, que no había dejado de reclamar su control. No obstante, todas las actividades se realizaban con una estricta separación de sexos. 
aire libre, en las que la vida reviente, el tallo se yerga desafiando al viento y los colores se muestren vivos y centelleantes. Hemos de vivir de cara al soß.

Estas actividades de verano ofrecían a las afiliadas más jóvenes, al igual que a los chicos, la oportunidad de pasar veinte días al aire libre completando su formación nacionalsindicalista y católica, así como fortaleciendo su salud y su cuerpo mediante la práctica regular de educación física y un estricto control de la higiene. Sin embargo, se advertía que el término «campamento» no debía llevar a engaños, pues las ocupaciones femeninas no eran una réplica exacta de las de los muchachos: mientras que los futuros soldados y trabajadores españoles se involucraban en ejercicios de inspiración militar, ellas, destinadas a convertirse en madres y amas de casa, recibían una educación especialmente concebida para su posterior reclusión en el hogar y su ineludible responsabilidad maternal. En definitiva, la dicotomía exterior/ interior se mantenía incluso «al aire libre».

¿Campamentos femeninos? ¿Qué hacen las mujeres en el campocampamento? Pues, amigos, muchas cosas. Primero, y aunque parezca contradictorio, las futuras mujeres de la Falange hacen en el campo, ante todo, hogar.

Así pues, se imponía un discurso diferenciado que dirigía a niñas y niños hacia sus respectivos destinos sociales, ambos entendidos como formas complementarias de contribución a la Patria: el trabajo asalariado, el ejército o los puestos de dirección política para ellos; la maternidad y las labores domésticas para ellas. De ese modo, se definían desde la infancia los roles de género, concibiendo además a las personas, no como individuos libres, sino como medios e intermediarias de los fines y la gran política del Estado.

Si ellas, la ilusión, son preparadas para regir nuestros hogares - célula fundamental del gran cuerpo del Estado- ellos, la inteligencia y el brazo, han de serlo para la sagrada misión de empuñar los mandos nacionales y conducir a España hacia la meta gloriosa que le fijó el Caudillo y que reafirmaron con sus sacrificios tantos y tantos camaradas entregados en plena juventud.

3 «El cuerpo fuerte». La Nueva España, 28 de diciembre de 1937: 6.

4 «El campamento femenino, continuador del hogan». La Nueva España, 24 de junio de 1942: 5.

5 «El Frente de Juventudes de Asturias rinde cuentas de su labor en el año que acaba de pasar». La Nueva España, 5 de enero de 1943: 11. 


\section{Los CAMPAMENTOS FEMENINOS EN ASTURIAS}

En el verano de 1938 se instaló en un palacio de la localidad de Andés, en el concejo de Navia, el primer campamento femenino celebrado en Asturias, conocido como el «Campamento Teruel $»^{6}$. Durante los dos años en los que se mantuvo acudieron a este lugar afiliadas de Asturias, Zamora y Salamanca en grupos de entre 80 y 120 chicas, llegando a haber hasta cinco turnos anuales de entre quince y veinte días cada uno.

En 1940 estas actividades se trasladaron a Poo de Llanes, donde se emplazó el «Campamento 14 de Junio» ${ }^{7}$. Esta vez se ubicó en una casa de indianos de principios de siglo que, según se relataba en la prensa, se encontraba «un poco enmohecida por el abandono prolongado y un mucho maltratada por el uso a que la destinaron los marxistas en la época de su dominación» ${ }^{8}$. El ambiente era descrito como un paraíso idílico, «un escenario de maravilla» donde «los bellos sueños de la Falange se van traduciendo en realidades magníficas», en el que todo era perfecto, «[a]mplias y claras las habitaciones, abundante y sabrosa la comida, soleada y estallante de verdor la huerta incomparable, admirables los contornos...». El optimismo exacerbado se extendía al discurso sobre las enseñanzas recibidas por las niñas, que debían ser formadas «en la adoración a Dios, en la veneración por la Patria y en el culto al hogar, piedra angular de la grandeza de un pueblo» ${ }^{10}$. La tríada femenina por excelencia, «Dios, Patria y Hogan», tomaba cuerpo en el tipo de

$6 \mathrm{El}$ nombre parece una alusión a las operaciones militares que tuvieron lugar en Teruel entre diciembre de 1937 y febrero de 1938 y que culminaron con su caída definitiva en manos de los sublevados. Además, también las mujeres que colaboraron en la defensa de la ciudad frente a los republicanos fueron especialmente recordadas por la Sección Femenina, sobre todo por su labor en los hospitales (Suárez Fernández, 1992: 85). Asimismo, cabe señalar que, al igual que las turolenses, las enfermeras ovetenses también fueron muy alabadas por su papel en el cerco de Oviedo y por su participación en la evacuación del Hospital Provincial durante la ofensiva de febrero de 1937.

7 Este nombre posiblemente hace referencia a los sucesos ocurridos el 14 de junio de ese mismo año, día en que se produjo la caída de París en manos de los nazis y la ocupación de Tánger por parte de tropas españolas. Más tarde pasó a denominarse «Campamento Don Juan de Austria».

8 «Campamentos del Frente de Juventudes». La Nueva España, 28 de agosto de 1943: 5. Véase también «La Casona de Poo ya se alegra con la risa de las niñas». La Nueva España, 18 de agosto de 1942: 5.

9 «Campamentos de Organizaciones Juveniles». La Nueva España, 11 de agosto de 1940: 4. 10 «Campamentos del Frente de Juventudes». La Nueva España, 28 de agosto de 1943: 5. 
actividades realizadas en estos albergues estivales y, en realidad, se extendía a toda iniciativa educativa orientada hacia las mujeres.

Al igual que en el caso del «Campamento Teruel», todos los veranos se encontraban en Poo de Llanes entre 100 y 150 chicas menores de diecisiete años en cada uno de los cuatro turnos de veinte días que solía haber, alargándose la temporada incluso hasta septiembre y octubre. Además de las asturianas, también acudían jóvenes de distintos lugares de España, preferentemente del interior, como Zamora, Valladolid, Palencia, Segovia, Burgos, Madrid, Toledo o Extremadura.

\section{Armonía, unidad y CAMARAdería}

Uno de los objetivos más importantes, además de la enseñanza de disciplina y el fortalecimiento de la salud de las acampadas, era el de acercar a las distintas clases sociales. Por ello, pretendían mostrar a las niñas de clase alta los valores de la austeridad y la humildad, a la vez que hacían posible que las más desfavorecidas pudieran pasar unos días de vacaciones en la playa o la montaña. Así lo aseguraba Carmen Werner, Regidora Central de Organizaciones Juveniles de la Sección Femenina, en un acto celebrado en el Campamento de Navia en agosto de 1938, al proclamar que una de las metas de estas iniciativas era la de «unir más estrechamente a las camaradas de la ciudad y el campo, a las ricas y a las pobres». De ese modo, a pesar de que las circunstancias las colocarían en lugares distintos, quedarían «unidas por esa afección que nace de la comunidad de destino y en la conciencia de que todos somos colaboradores en la tarea de engrandecimiento de España» ${ }^{11}$. Las referencias a este tema eran abundantes, tanto en la prensa como en la documentación interna.

Alli, en un ambiente de perfecta camaradería, se hermana la Flecha de familia bumilde, la que carece de medios económicos y encuentra asi un paréntesis de descanso y alegría en su vida, con aquella otra nacida en más alto medio, de desahogada posición, que ganó como premio estos veinte días de estancia en el Albergue. Dentro de sus muros no hay diferencia ni distancias; sencillamente se logra la hermandad entre las clases sociales en el grato ambiente que creó para estas niñas la Falange. Son iguales sus trajes de Campamento y

11 «Del Campamento de Navia». La Nueva España, 17 de agosto de 1938: 4. 
un mismo toque las despierta al brillar el sol. Sus manos alzan las banderas y sus plegarias resuenan con eco común ante la Cruz de los Caídos ${ }^{12}$.

Por tanto, en el discurso ideológico sobre los campamentos podemos ver el intento de poner fin a la lucha de clases, así como el objetivo de implantar una sociedad armónica y sin discrepancias entre el capital y el trabajo. La intención era conseguir que, a través de la convivencia, se olvidasen «antiguos resentimientos», logrando «una leal camaradería entre todas ellas» ${ }^{13}$. En este sentido, la retórica triunfalista hablaba del fin de las diferencias sociales, pero más bien lo que se buscaba era acabar con el movimiento obrero, creando una imagen utópica de cooperación entre clases y fomentando un conformismo basado en la idea de que cada grupo económico y cada sexo tenía una misión y un lugar que ocupar en la sociedad. Las chicas de distintos ambientes debían aprender a tratarse como camaradas, a comprenderse y relacionarse entre sí, pero en ningún caso se contemplaba una alteración del orden establecido, un cambio de roles o un ascenso de las de clase trabajadora. Así pues, los campamentos constituían un paréntesis y una fachada que ocultaban una realidad en la que sí había desigualdades. Además, como recordaba Carmen Werner, a las jóvenes les convenía «relacionarse con intimidad y confianza, acabando con los conceptos de diferenciación, conociéndose cada una, en su posición económica, pero considerándose iguales en su condición de mujer» ${ }^{14}$. Como vemos, se esperaba que las chicas respetasen la existencia de clases sociales, mientras que la pertenencia a un sexo determinado aparecía como una categoría que trascendía las barreras económicas. Al mismo tiempo, tanto el género como la clase eran considerados elementos naturales e inalterables y no como construcciones sociales.

En la misma línea, se aspiraba a eliminar diferencias nacionales, bien mediante la convivencia de niñas de diferentes puntos de España, bien con el aprendizaje de canciones y bailes de las distintas regiones, creando asimismo la ilusión de la España única e indivisible.

En los campamentos se inculcan y "viven" las bellas inquietudes y altos ideales de nuestro Movimiento nacional. Aprenden las canciones regionales,

12 «Comentario. Albergues de verano». Voluntad, 21 de junio de 1945: 4.

13 Carta de la Regiduría Central de Juventudes Femeninas, 25 de junio de 1946, Archivo Histórico de Asturias (AHA), caja 5020/1.

14 «Se inauguró el Campamento femenino de Navia». La Nueva España, 11 de agosto de 1938: 3 . 
Cantos y danzas, romances y leyendas, tradición e bistoria en forma amena. Sano esparcimiento de su espiritu que las permite conocer y amar más entrañablemente a esa unidad indivisible y trascendental que es nuestra Patria ${ }^{15}$.

Por otro lado, los campamentos también estaban abiertos a niñas y niños de origen español residentes en el extranjero con el propósito de que, cuando regresaran a su país, lo hicieran «pensando en español, sintiendo en español, reaccionando en español, con el ¡Arriba España! en los labios y el nombre de Franco en el corazón» ${ }^{16}$.

\section{4. «Dios, Patria y Hogar». La Formación Recibida EN LOS CAMPAMENTOS DE JUVENTUDES FEMENINAS}

La formación en los campamentos debía ser tanto física como espiritual o moral y, por supuesto, política. Además, en el caso de las niñas, la estancia estaba concebida como una iniciación al hogar, que sería la misión que tendrían que cumplir una vez que se convirtieran en mujeres.

Si la gran empresa de la mujer es el hogar, la vida de un campamento femenino es un reflejo del mismo. En él los tres valores consustanciales de la mujer falangista, la Religión, la Patria y la Familia, toman forma con la crur, las banderas y la casa que lo integran ${ }^{17}$.

La rutina y el horario en estos campamentos de «futuras amitas de casa», tal y como se las describía en la prensa, era de severa disciplina e incluía una gran cantidad de actividades: clases de canto, donde se ensayaban canciones con motivos regionales y patrióticos; interpretación de bailes típicos de las distintas zonas geográficas, competiciones y exhibiciones deportivas, trabajos manuales que preparaban a las niñas para menesteres domésticos, lecciones de religión y de política, etc. Una de las ocupaciones más populares en la que se entretenían era el llamado «Fuego de Campamento», una ocasión en la que

15 «El Frente de Juventudes prepara sus campamentos». La Nueva España, 4 de julio de 1943: 3.

16 «Campamentos de Verano del Frente de Juventudes». La Nueva España, 8 de agosto de 1942: 5.

17 «Frente de Juventudes. Campamentos femeninos». La Nueva España, 5 de julio de 1942: 5. 
las jóvenes se reunían para cantar, bailar, contar historias, hacer bromas, etc. Otra de las actividades era «la Hora del Romance», momento del día que se reservaba para recitar y escenificar poesías españolas, preferentemente con un contenido épico destinado a difundir entre las acampadas las leyendas y gestas atribuidas a los héroes españoles en las épocas medieval y moderna ${ }^{18}$. Contaban también con una biblioteca con libros sobre religión o formación social y política, además de ejemplares para el ocio que buscaban encauzar el interés de las niñas hacia la literatura clásica española. Los asesores de religión advertían sobre la necesidad de censurar correctamente estas lecturas para evitar la toma de contacto de las jóvenes con obras consideradas perniciosas.

Se realizaban también excursiones, por lo general a lugares con un significado religioso o patriótico. Por ejemplo, los viajes a Covadonga eran los más habituales en el caso de Asturias. El aspecto cristiano y nacionalista se completaba con las oraciones en torno a la Cruz de los Caídos, el izamiento y arriamiento de las banderas, la exaltación de ciertos acontecimientos históricos, etc. De hecho, la formación en política y religión se concebía como un estado permanente que debía impregnar toda la vida en el campamento (Tabla I).

18 «a Hora del Romance. En los campamentos femeninos». La Nueva España, 1 de julio de 1942: 3. 
Tabla I. Formación religiosa y política en los campamentos

\begin{tabular}{|c|c|}
\hline \multicolumn{2}{|r|}{ Formación religiosa } \\
\hline Oraciones & $\begin{array}{l}\text { Tanto por la mañana como por la tarde. Podían hacerse de pie } \\
\text { o de rodillas }\end{array}$ \\
\hline Santa Misa & Se enseñaba a las niñas a dialogar en latín \\
\hline \multicolumn{2}{|l|}{ Comunión } \\
\hline Clases de música & $\begin{array}{c}\text { Además de las canciones regionales, aprendían algunos cantos } \\
\text { gregorianos y religiosos }\end{array}$ \\
\hline Comida & Con bendición de la mesa y oraciones señaladas \\
\hline $\begin{array}{l}\text { Redacción de un } \\
\text { periódico }\end{array}$ & $\begin{array}{l}\text { Se incluían comentarios sencillos y breves sobre el santo o } \\
\text { festividad más relevante de aquellos días }\end{array}$ \\
\hline \multicolumn{2}{|l|}{ Clases de religión } \\
\hline $\begin{array}{c}\text { Fuego de } \\
\text { Campamento }\end{array}$ & Algunas charlas se dedicaban a temas religiosos \\
\hline \multicolumn{2}{|r|}{ Formación política } \\
\hline $\begin{array}{l}\text { Izar y arriar } \\
\text { banderas }\end{array}$ & $\begin{array}{c}\text { Se enseñaba a las niñas el simbolismo de esta ceremonia y } \\
\text { a asistir a ella con corrección y respeto. Además, se leía una } \\
\text { consigna de José Antonio o de Franco y se cantaba siempre el } \\
\text { Cara al Sol }\end{array}$ \\
\hline $\begin{array}{l}\text { Mantenimiento del } \\
\text { albergue }\end{array}$ & Debían arreglar diariamente la Cruz de los Caídos \\
\hline Clases de música & $\begin{array}{l}\text { Aprendían himnos y canciones del Movimiento y de la Guerra } \\
\text { Civil }\end{array}$ \\
\hline $\begin{array}{l}\text { Redacción de un } \\
\text { periódico }\end{array}$ & $\begin{array}{l}\text { Se comentaban las lecciones de nacionalsindicalismo y se } \\
\text { exaltaban las figuras de José Antonio y del Caudillo }\end{array}$ \\
\hline $\begin{array}{c}\text { Clases de } \\
\text { nacionalsindicalismo }\end{array}$ & \\
\hline $\begin{array}{l}\text { Fuego de } \\
\text { Campamento }\end{array}$ & $\begin{array}{c}\text { Se trataban temas de historia de la Falange y de la Guerra } \\
\text { Civil, hechos heroicos de camaradas de la Sección Femenina } \\
\text { condecoradas con la } Y \text {, etc. }\end{array}$ \\
\hline
\end{tabular}

Fuente: Elaboración propia a partir de datos de una carta de la Regiduría Central de Juventudes Femeninas, 25 de junio de 1946, AHA, caja 5020/1.

El papel de persuasoras y educadoras en el seno de la familia que se atribuía a las mujeres explica la especial importancia que tenía su formación moral. Se esperaba que ellas fueran las encargadas de la supervivencia de los principios ideológicos del Régimen, sobre todo a través de la trasmisión de los valores oficiales a sus parientes más cercanos. Por ello, si a la población había que captarla «desde la cuna», primero había que llegar a las mujeres, en cuyas manos recaía gran parte de la educación de las nuevas generaciones. En definitiva, se les asignaba la tarea de reeducar a la población: «los hombres 
del mañana serán lo que sean las madres de hoy», se reiteraba ${ }^{19}$, de modo que debían ser las más patriotas, las más falangistas y las más cristianas. Esto no puede ser desvinculado del propio ámbito de la maternidad, entendida en este caso no como un acto de reproducción biológica, sino social y cultural.

La elevación del nacionalsindicalismo a la categoría de religión, con sus mártires, dogmas, símbolos y oraciones también era evidente. Además, es reseñable el sentimentalismo que teñía los textos sobre este tema en los medios de comunicación. Por ejemplo, esto es lo que, según el diario La Nueva España, narraba una de las asistentes al Campamento de Navia en el verano de 1938:

Estamos alegres y satisfechas, deseando que se termine un día para que llegue el otro y encontrarnos con nuevos cantos, amenas "charlas" de Historia y Literatura; pero lo que más nos gusta, lo que llama grandemente nuestra atención es cuando nos hablan de Nacionalsindicalismo. Y se da el caso general en este gusto. Cuando nos hablan de José Antonio, de su vida, de su doctrina, de las persecuciones a que se vio sometido con los suyos. De tantos y tantos héroes anónimos que mueren por Él, de nuestra bandera... Las niñas, emocionadas, lloran ${ }^{20}$.

19 «Semana contra la mortalidad infantil». La Nueva España, 1 de octubre de 1940: 3.

20 «Campamento de Verano de las O. J. Femeninas». La Nueva España, 13 de septiembre de 1938: 3. 
Tabla II. Horario de los campamentos femeninos

\begin{tabular}{|r|l|}
\hline \multicolumn{2}{|l|}{ Mañana } \\
\hline $7: 00$ & Diana y aseo \\
\hline $7: 30$ & Izar bandera y oración \\
\hline $8: 00$ & Desayuno \\
\hline $8: 30$ & Arreglo del campamento \\
\hline 9:30 & Clase de música \\
\hline $10: 30$ & Gimnasia \\
\hline $11: 00$ & Marcha a la playa y baño \\
\hline $12: 30$ & Ducha \\
\hline $13: 00$ & Comida \\
\hline & \\
\hline $13: 30$ & Reposo \\
\hline $14: 30$ & Arreglo de enseres \\
\hline 15:00 & Trabajos manuales \\
\hline 16:00 & Escritura del diario y redacción del periódico \\
\hline $17: 00$ & Merienda \\
\hline $17: 30$ & Santo Rosario, clase de Religión o Nacionalsindicalismo \\
\hline $18: 30$ & Marcha, Hora del Romance y deporte \\
\hline $20: 30$ & Arriar la bandera y Angelus (los sábados se cantará La Salve) \\
\hline $21: 00$ & Cena \\
\hline $21: 30$ & Fuego de Campamento \\
\hline $22: 30$ & Cambio de servicios y silencio \\
\hline
\end{tabular}

Fuente: La Nueva España, 27 de junio de 1942: 5.

Aunque el ejercicio físico y el deporte tenían una importancia fundamental, no se abandonaban las actividades reposadas y «de interion», que suponían un entrenamiento para el futuro. Por ello, la casa del campamento femenino tenía un significado especial del que carecía en el caso masculino. De igual forma, el adorno y cuidado de las habitaciones, el cultivo de flores y plantas o la confección de prendas para bebés eran tareas a las que se prestaba mucha atención. En cambio, en lo que se refiere a los chicos apenas se mencionaban aspectos que no tuvieran que ver con la vida deportiva y castrense al aire libre y se observa un menor interés por describir el edificio 
o las dependencias en las que habitaban. Por ejemplo, en el horario de los campamentos femeninos se fijaban ocupaciones como el «arreglo del campamento», «arreglo de enseres» o «trabajos manuales», que no estaban pensados para los varones (Tabla II). En contraposición, ellos tenían actividades como asambleas, formaciones, instrucciones tácticas, relevos de guardia, etc. ${ }^{21}$

El afán de las Organizaciones Juveniles por inculcar la vida hogareña en sus afiliadas era evidente, lo que en el caso de Asturias les llevó incluso a proponer una iniciativa que consistía en acompañar a las niñas todos los domingos a una finca de recreo para realizar prácticas de economía doméstica. Allí pretendían enseñarles a limpiar la casa, a amueblarla «dentro de las normas del gusto y la economía; a guisar la comida que previamente comprarán en mercados y comercios», etc., todo teñido de «un sentido doméstico, alegre, económico y artístico del hogar...» ${ }^{22}$.

\section{SALUd E HigIENE EN LOS CAMPAMENTOS}

Las enseñanzas de religión y política estaban destinadas a crear mujeres «sanas de espíritu», pero también era fundamental que éstas fueran «sanas de cuerpo» para que estuvieran en condiciones de dar a luz a hijos fuertes, los futuros hombres y madres de España. De hecho, no es descabellado afirmar que la formación física de ambos sexos era el principal fin de estas actividades estivales, al menos durante estos primeros años de la posguerra. Esto conecta directamente con la política demográfica del Régimen, un asunto que parecía quitar el sueño a un cierto grupo de políticos, médicos y eclesiásticos que se sumaron con todos los medios a su alcance al objetivo de aumentar la natalidad y reducir la mortalidad infantil. Sin embargo, la preocupación por la demografía no se entendía sólo desde un punto de vista cuantitativo, sino también cualitativo, pues era necesario mejorar la salud de hombres y mujeres en un contexto en el que tanto la cantidad de población de una nación como la fortaleza física de sus habitantes eran consideradas como el reflejo de su importancia política, poderío militar y prosperidad

21 «Crónica del Campamento de Organizaciones Juveniles». La Nueva España, 15 de julio de 1938: 4.

22 «Las mujeres de la Falange, en la guerra y en la paz». La Nueva España, 1 de marzo de 1938: 4. 
económica. Por ello, la natalidad, la higiene y la salud se politizaron, pasando a ser pruebas de patriotismo y de masculinidad.

No hay riqueza mayor para un país que la representada por sus bijos. Ningún pueblo más rico que el que acusa un excedente de natalidad, signo de juventud, de virilidad ${ }^{23}$.

La ventaja más anunciada de los campamentos falangistas era precisamente su capacidad para robustecer la salud y fuerza corporal de sus asistentes. Al mismo tiempo, el culto al cuerpo, el entusiasmo por el deporte, la guerra o la vida al aire libre que se observa en los textos destinados a la juventud, tanto masculina como femenina, estaban impregnados de ideas sobre la mejora de la raza y su relación con los deseos de dominio imperialista. En el caso de los chicos está claro, los futuros trabajadores y soldados españoles debían ser atléticos, pues sólo una población vigorosa y sana era considerada digna de crear y sostener un imperio.

La juventud hispana se cr[i] ará fuerte, subirá los riscos empinados sin cansarse, andará leguas y leguas como si tal cosa, y mañana podrá decir en voz. muy alta que somos los mejores, que tenemos derechos sobrados para mandar al mundo y para que todas las naciones se inclinen hacia nosotros ${ }^{24}$.

Como podemos apreciar, la salud no se entendía como un fin en sí mismo, pero además tenía significados distintos para hombres y para mujeres. Para ellas era importante debido a su papel de madres de las futuras generaciones y, por tanto, de garantes de la supervivencia física e ideológica de la nación.

Soñad, niñas, con ese abrazo donde la hermandad de la Camisa Azul os proporciona, no sólo las caricias de la Falange en la pureza del aire y frescura del mar, sino que, os formará para que seáis mañana mujeres fuertes de cuerpo y espíritu, dignas madres de esa raza viril que España necesita para su Imperio. El CAMPAMENTO os hará ahora niñas alegres y disciplinadas con el fin de que un día lleguéis a ser lo que España quiere de vosotras, mujeres nacionalsindicalistas. Esta palabra que hoy quizá no comprendéis, lo encierra todo: Mujer nacionalsindicalista es virtud, es abnegación, es amor, es sacrificio,

23 «Estadística y natalidad». La Nueva España, 15 de julio de 1943: 3.

24 «Una juventud heroica y decidida». La Nueva España, 12 de junio de 1938: 9. 
es la propia alma de España que se derrama por manos y labios de mujer para hacer el bien a sus hijos ${ }^{25}$.

En definitiva, las prácticas deportivas y de higiene eran concebidas como una forma de lograr un cuerpo fuerte para la maternidad, lo que de hecho se consideraba un deber nacional. "[H]aremos que sean deportivas», se decía en una emisión de radio dedicada a las juventudes femeninas, pero «sin exhibicionismos ni estridencias: en sentido higiénico de mejora de la raza, primordial deber de todo buen patriota $\rangle^{26}$. Por otro lado, se confiaba en que la salud de las mujeres redundaría en beneficio de la de sus parientes más cercanos y favorecería la construcción de familias extensas. Asimismo, la gimnasia se entendía como un medio para que adquirieran una disciplina férrea que las alejara de vicios perniciosos.

Al mismo tiempo, era preciso desterrar el tradicional estereotipo de belleza frágil, incompatible con una propaganda que exigía a las mujeres encargarse de familias numerosas y que descargaba sobre ellas gran parte de la responsabilidad y la culpa por los altos índices de mortalidad infantil existentes en el país ${ }^{27}$. La debilidad física o las enfermedades eran consideradas como una tragedia reproductiva, de modo que también se alertaba de la importancia de elegir una pareja sana y sin vicios o dolencias, una cuestión fundamental si tenemos en cuenta que la razón de ser del matrimonio era única y exclusivamente la reproducción.

Y las mujeres debemos recordar que la palidezy la anemia, no sólo puede sernos fatal para la salud, sino que ni siquiera es ya de buen tono. La mujer debe ser robusta. No bay mijer elegante sin mujer. Y no hay mujer donde sólo hay forma femenina, consumida la naturaleza por la enfermedad. Nada

25 «La voz de España». La Nueva España, 3 de julio de 1938: 7.

26 «Anoche se dio una emisión de radio dedicada a las flechas». La Nueva España, 6 de mayo de 1938: 7.

27 La mortalidad infantil era atribuida sobre todo a la ignorancia de las madres, que se manifestaba presuntamente en su desconocimiento de los principios básicos de puericultura, su reticencia a acudir a las consultas de los médicos y en el mantenimiento de prejuicios, costumbres o prácticas erróneas que conllevaban un peligro para la vida de niños y niñas. Esta creencia suponía una culpabilización de las mujeres, así como una descontextualización de la mortalidad infantil con respecto a la realidad socioeconómica. Para más información sobre este tema véase Jiménez Lucena y Ruiz Somavilla (2001), Bernabeu-Mestre (2002) o Palacio Lis (2003). 
más inelegante que una tísica o una linfática de carnes flácidas y músculos de manteca.

Yo no sé pasar a otro párrafo sin escribir un último pensamiento acerca de ello: sí, por uno de tantos azares como se realizan, un hombre débil o una mujer enfermiza llegasen a interesar, y este interés les llevase al matrimonio, tened por descontada una inmensa catástrofe. Vendrán desilusiones y tristes realidades. $Y$ los anhelos no satisfechos interpondrán entre marido y mujer una tercera persona que representará la pazy la alegría rotas para siempre ${ }^{28}$.

Si bien el discurso sobre los campamentos estaba teñido de referencias a la raza como sinónimo de salud y fortaleza física, éstas se entremezclaban con una insistencia en la idea de «Hispanidad» como fundamento de la «raza española», es decir, en el deseo de volver a una época supuestamente heroica y gloriosa en la que España era una nación poderosa que dominaba la política internacional ${ }^{29}$. Esto se ajusta a lo que han destacado autoras como Mary Nash (1996) o Isabel Jiménez Lucena (1997), quienes coinciden en subrayar que las inquietudes eugenésicas y raciales poseían en nuestro país unas características peculiares. En la España de Franco el programa racial tenía más que ver con un componente religioso, político e ideológico que con el estrictamente biológico. Como indica Mary Nash, «la españolización de la identidad cultural era la base de la política racial franquista, que no contemplaba el genocidio ni la esterilización $»^{30}$, pero sí la reeducación de la población infantil para conseguir una sociedad homogénea, reprimiendo los nacionalismos periféricos o las identidades que no concordaran con la visión oficial. De ese modo, los discursos sobre la corrección moral o religiosa se confundían con los que versaban sobre la salud física hasta el punto en que, según asegura Isabel Jiménez Lucena, «en muchas ocasiones es difícil distinguir si el término «raza», «racial»y otros equivalentes se refieren a aspectos biológicos o a aspectos morales e ideológicos» ${ }^{31}$. De hecho, lo físico se hacía depender de lo moral, de modo que se concluía que un cuerpo sano no era posible sin un alma cristiana.

28 «El cuerpo fuerte». La Nueva España, 28 de diciembre de 1937: 6.

29 Para más información sobre las particularidades de la política racial franquista véase Polo Blanco (2006).

30 Nash (1996: 297).

31 Jiménez Lucena (1997: 121). 
En todo caso, los textos más exaltados en relación a los campamentos juveniles corresponden a finales de los años treinta, cuando aún se pueden leer encendidos sermones sobre la decadencia de la raza. En cambio, a medida que nos acercamos a 1945 se insiste cada vez más en el cristianismo como base natural de «lo español». Ésta es la tendencia general que se puede apreciar en la prensa falangista asturiana en lo que concierne a los escritos dirigidos a las mujeres, que pasaron de tener un contenido fuertemente ideológico a convertirse en páginas con consejos sobre moda, belleza o labores domésticas. No obstante, durante estos años el aspecto sanitario continuó siendo uno de los fines y argumentos propagandísticos principales $^{32}$. Por ello, no es de extrañar que Isabel Jiménez Lucena opine que «los Campamentos, Albergues y Estaciones preventoriales, aunque no fuesen instituciones de carácter asistencial, tenían en sí una finalidad médica» ${ }^{33}$.

Tanto la limpieza individual como la de las distintas dependencias eran partes importantísimas de la rutina y disciplina diarias y tenían el objetivo de inculcar en las chicas el sentido higiénico personal y del hogar. Ya antes de ingresar en los campamentos cada muchacha debía superar un examen médico que dictaminase que no tenía parásitos o alguna enfermedad contagiosa que pudiera afectar a las demás. Asimismo, según normas de la Regiduría de Divulgación y Asistencia Sanitario-Social de la Sección Femenina, la vigilancia de la salud y profilaxis de las jóvenes debía ser muy estrecha, lo que servía para corregir y unificar hábitos y modales, aunque también para mejorar unas condiciones higiénicas que no hacían sino reflejar la miseria de la posguerra.

\begin{abstract}
Al llegar las flechas al albergue se las pesará, tallará y medirá, anotando estos datos en la ficha médica, se hará un reconocimiento completo a la flecha y una revisión de bigiene detalladísima, (...) y como consecuencia de la cual serán devueltas todas aquellas que fuesen parasitadas (...) y todas las que no lleven las fichas médicas en condiciones. Se confeccionará un parte en el que se haga constar el estado de limpieza en que llegasen las niñas, especificándose la local y provincia a que pertenecen las flechas que fueron en malas condiciones
\end{abstract}

32 No fue el único caso en el que la política sanitaria se utilizó con fines proselitistas. La cuestión de la sanidad como instrumento político en el Franquismo ha sido estudiada en el artículo de Jiménez Lucena, Ruiz Somavilla y Castellanos Guerrero (2002). Véase también Jiménez Lucena (1997).

33 Jiménez Lucena (1997: 121). 
(...) Se aprovechará el reconocimiento general para advertir a las niñas de cómo ha de ser su higiene mientras permanezcan en el Albergue (...) Se verá a aquellas que lleven melena descuidada y se tomarán las medidas necesarias para que su aspecto sea lo más limpio posible. Se les avisará de que se va a hacer esta revisión frecuentemente y por lo tanto deben estar siempre limpias para sufrir esta inspección. Se vigilará el que a las horas establecidas se limpien las flechas los dientes, pues si se deja a su iniciativa sin recordarlo todos los dias pasará el tiempo sin que lo hagan. Se vigilarán las duchas, no permitiéndose que se duchen mal o sin jabón y se comprobará que, en efecto, las niñas están limpias (...) Se vigilará a las niñas mientras se acuestan ocupándose de que dejen la ropa de manera adecuada, las ventanas abiertas y que se acuesten con su correspondiente camisón y sin la ropa que usaron durante el día ${ }^{34}$.

Si obviamos la ausencia de privacidad que nos sugieren estas palabras, todo esto nos puede hacer pensar que, en el ámbito sanitario, la pertenencia a la Sección Femenina o al Frente de Juventudes tenía sus ventajas. Pongamos como ejemplo la vehemencia con que se insistía en los reconocimientos médicos obligatorios de las afiliadas o la preferencia que las militantes podían obtener a la hora de conseguir una plaza en hospitales, dispensarios antituberculosos, sanatorios, estaciones preventoriales, etc., cuyos gastos podían estar abonados total o parcialmente por la Sección Femenina en caso de dificultad económica de la camarada.

Junto con las detalladas descripciones de los servicios sanitarios y de las instalaciones de lavabos, duchas y agua corriente ${ }^{35}$, el discurso sobre lo nutritivas y abundantes que eran las comidas servidas en los campamentos era otro gran argumento proselitista, esta vez destinado a convencer a una población hambrienta de las bondades del Régimen. Además, con ello se completaba la imagen de una sociedad ideal: disciplinada, obediente, unida, sana y bien alimentada. Sin embargo, ésta disfrazaba una realidad que poco

34 Carta de la Regidora Central de Divulgación, Consuelo M. Monasterio, 11 de junio de 1945, AHA, caja 4831/1.

35 Así se describían, por ejemplo, los servicios higiénicos del campamento de Poo de Llanes: «En los sótanos del edificio, ventilados y luminosos, con las paredes cubiertas totalmente de baldosines azules, con su cielo raso y sus columnas revestidas de un blanco inmaculado, se ha procedido a la instalación de treinta y tres lavabos de porcelana, blanca asimismo, y de doce duchas que no tienen nada que envidiar a las más perfectas. El agua corriente, en la cantidad necesaria para cubrir todas las atenciones, es el complemento preciso para que los servicios sanitarios estén cubiertos a gusto del más exigente» («Campamentos de Organizaciones Juveniles». La Nueva España, 11 de agosto de 1940: 4). 
tenía que ver con lo que se relataba en los medios de comunicación. Aun así, parece que, efectivamente, la alimentación en los campamentos asturianos no era nada despreciable. Las facturas conservadas en el Archivo Histórico de Asturias correspondientes a los organizados en el verano de 1945 permiten comprobar el tipo de adquisiciones que se hacían: cientos de kilos de fruta (ciruelas, plátanos, manzanas o naranjas), hortalizas variadas, embutidos, sardinas, bonito, huevos, leche, galletas, carne de ternera, especias, aceitunas, anchoas, sopa, queso, manzanilla, pescado, almejas, té y achicoria e incluso pasteles, bombones, flanin, etc. ${ }^{36}$

Para acabar este capítulo es necesario aludir brevemente al caso de las estaciones preventoriales, establecimientos que cumplían el programa formativo de los campamentos, pero intensificando el aspecto sanitario, pues estaban destinadas a chicas y chicos con algún problema de salud, aunque no con enfermedades graves o contagiosas. En Poo de Llanes también llegó a funcionar una estación preventorial para juventudes femeninas, al menos entre diciembre de 1942 y abril de 1943, cuando acudieron varios turnos de niñas, muchas de ellas procedentes de las cuencas mineras.

\section{Albergues para afiliadas al Sindicato Español Universitario. El Albergue de Barro (Llanes)}

Similares a los campamentos del Frente de Juventudes eran los albergues destinados a las universitarias, gestionados por el Sindicato Español Universitario (SEU). Dentro de la estructura del Sindicato existía una sección que encuadraba a las estudiantes, pero el interés de Pilar Primo de Rivera por controlar a estas mujeres hizo que de hecho hubiera una doble dependencia: por un lado, formaban parte del SEU, pero a la vez también obedecían a la Sección Femenina ${ }^{37}$.

A pesar de que la educación superior no estaba entre los destinos preparados para las mujeres, era conveniente canalizar de forma adecuada esa formación para que, una vez terminados los estudios y, con independencia de que obtuvieran un trabajo remunerado (a poder ser, en oficios «propiamente femeninos»), estuvieran dispuestas a aceptar su papel de amas de casa. La enseñanza universitaria era estimada como de utilidad para algunas, pues podía contribuir a una mejor educación de los hijos y a una más adecuada

36 AHA, caja 4702/1.

37 Ruiz Carnicer (1996: 446-496). 
dirección del hogar. ${ }^{38}$ También, como critica Miguel A. Ruiz Carnicer, se reconocía que podía servir para perfeccionar a la mujer «con vistas a su labor de acompañamiento y apoyo al hombre, como forma de hacerle más agradable su descanso» ${ }^{39}$. Precisamente en esta línea se pronunciaba José Miguel Guitarte, Jefe Nacional del SEU, en el acto de clausura del primer albergue universitario femenino celebrado en Asturias: «[q]ue el hombre sea, en todo momento, el ser que crea; pero que la mujer sea también, en todo instante, el ser inspirador de las creaciones masculinas», recordaba a las estudiantes ${ }^{40}$. Por ello, a las mujeres no les convenía mostrar tener más conocimientos que sus maridos para no atentar contra la superioridad del hombre y el alegre paternalismo que debían caracterizar a los buenos matrimonios cristianos.

Nos asusta, tanto para mujer propia o simplemente para amiga leal, la mujer que calla sin atreverse a formular controversia, como aquella otra que sabe tanto como nosotros y no nos mira con admiración cuando le explicamos un tema de mecánica o geopolítica. Y puestos a elegir, preferimos a aquella callada y silenciosa, que nos considera maestros de su vida y acepta el consejo y la lección con la bumildad de quien se sabe inferior en talento ${ }^{41}$.

Las alusiones a la inferioridad mental de las mujeres eran habituales $\mathrm{y}$, de hecho, la figura de la «intelectual» era aborrecida por recordar a las mujeres «frívolas» y «desfeminizadas» de la Segunda República. La cultura y la educación eran deseables e imprescindibles para las mujeres, pero debían tener un fin práctico: el de familiarizarlas con su rol de madres y con las tareas del hogar. Para conseguir una perfecta formación de las universitarias y no alejarlas de la misión que se les atribuía, la Sección Femenina contaba

38 La opinión de algunos médicos era aun más recalcitrante. Por ejemplo, el maternólogo Antonio Clavero Núñez aseguraba que el hecho de que las mujeres estudiaran carreras universitarias era «sencillamente, antibiológico», pues era desproporcionado «no al grado de inteligencia de la mujer, que la tiene superior al hombre para las cuestiones que son de la jurisdicción de su sexo, sino a la capacidad de resistencia física y mental, propia del varón, que es preciso tener para soportar el esfuerzo continuado que exigen estos estudios» (1943: 54). Asimismo, alertaba de la masculinización de las mujeres que se producía como consecuencia: «[a] la mujer que pasó su adolescencia y su juventud haciendo la vida de estudiante no le sale, desde luego, bigote, pero sus hábitos, y sobre todo su mente, se suelen virilizar» (1943: 53).

39 Ruiz Carnicer (1996: 483).

40 «Realidades del Nacionalsindicalismo». La Nueva España, 21 de agosto de 1940: 4.

41 Martín Gaite (1987: 68). 
con el Servicio Social ${ }^{42}$, de obligado cumplimiento para las estudiantes, así como con los albergues de verano. En este capítulo me centraré en los albergues organizados en Asturias, analizados a través de la información recogida en la prensa regional.

En el verano de 1940 se organizó en Barro (Llanes) el primer Albergue Nacional Femenino del SEU, al que asistieron alumnas de distintas provincias para convivir en una "comunidad casi monástica» durante veinte días ${ }^{43}$. Entre 1940 y 1945 acudieron universitarias de Oviedo, León, Salamanca, Zaragoza, Murcia o Madrid en un número que oscilaba entre las treinta y las sesenta muchachas por turno, habiendo por lo general dos turnos. Además, en Barro también tenían lugar los albergues masculinos del SEU, que se realizaban en tiempos separados a los de las chicas.

El patrón formativo que veíamos en los campamentos juveniles se repite en los albergues del SEU: fortaleza física y moral acompañada de enseñanzas del hogar y proselitismo religioso y político. Oraciones, clases de nacionalsindicalismo y religión, conferencias dadas por las propias estudiantes o por personal especializado, gimnasia y deporte o excursiones al aire libre eran las actividades más típicas. Por lo general, las jóvenes también se encargaban de exponer pequeñas lecciones diarias relacionadas con el nacionalsindicalismo o la religión, aunque también con otros temas de historia o literatura. Asimismo, se insistía con vehemencia en que estos albergues no eran espacios de recreo o de «cómodo veraneo», sino actos de servicio que facilitaban la canalización del ocio estival en el sentido deseado. Se evitaba así el temido periodo de desconexión con la juventud universitaria y, en definitiva, la interrupción de la política de adoctrinamiento.

Como ocurría en el caso de los campamentos, las albergadas se entrenaban para ser amas de casa atendiendo los propios servicios que reclamaba el albergue. Además, debían prometer servir a Falange con absoluta fidelidad: «[1]a que no observe esta norma será eliminada sin contemplaciones, como un miembro podrido que podría pudrir el cuerpo», decía el Jefe del Distrito

42 Baste recordar que la práctica totalidad de las materias teóricas del Servicio Social estaban relacionadas de un modo u otro con las labores domésticas y no con la formación intelectual o profesional de las universitarias.

43 Las referencias a la comunidad religiosa también se hacían en el caso de los chicos, que eran descritos como «medio monjes, medio soldados». 
Universitario de Oviedo en el acto de inauguración de los albergues de $1942^{44}$. La rutina diaria era similar a la de los campamentos y debía guiarse por una estricta disciplina, aunque también por una alegre y optimista camaradería.

\section{ConClusiones}

Visto todo esto, podemos decir que tanto en los campamentos como en los albergues se trataba de reproducir a pequeña escala el tipo de sociedad que se quería construir en España: mujeres y hombres fuertes físicamente, con una moral cristiana impecable, disciplina militar y capacidad para asumir con alegría el puesto que se les tenía reservado en función de su sexo y clase social. La propaganda sobre los albergues y campamentos esbozaba una imagen de la juventud que pretendía ser entrañable y envidiable, pero no hay que olvidar que ésta era la visión ofrecida desde el poder a través de los medios de comunicación. Éstos retrataban un cuadro uniforme que aspiraba a convencer de las bondades del proyecto franquista, pero que no hacía sino esconder la diversidad y enmascarar los conflictos y la heterogeneidad inherentes a la convivencia en sociedad, así como las propias dificultades de la posguerra. Esto plantea al menos dos interrogantes: ¿cómo eran percibidos los campamentos por los distintos grupos sociales? y ¿cómo vivieron las niñas y jóvenes estas actividades? Con ello me pregunto de qué manera asimilaron estas experiencias y en qué términos lo expresaban entonces y de qué forma lo harían ahora. Las dificultades para responder a estas cuestiones son evidentes y nos remiten a la importancia de recurrir a los testimonios orales como fuente de información.

Los problemas que se evidenciaron a la hora de conocer la historia de las mujeres, tradicionalmente más ligadas al ámbito de lo doméstico, han hecho necesario acudir a fuentes distintas, así como releer las ya conocidas con otros ojos. El tema de la infancia o de la juventud, también olvidado por la historiografía tradicional, no es en absoluto distinto y su relevancia para el caso de los estudios de género es incuestionable. Después de todo, es en las primeras etapas de la vida cuando se interiorizan los estereotipos y actitudes que dan lugar a las diferencias entre hombres y mujeres.

44 «Inauguración del Albergue Femenino del S. E. U. en Barro». La Nueva España, 7 de agosto de 1942: 3 . 


\section{BibliografíA}

Bernabeu-Mestre, Josep (2002). «Madres y enfermeras. Demografía y salud en la política poblacionista del primer franquismo, 1939-1950». Revista de Demografía Histórica 20 (1): 123-143.

Clavero Núñez, A. (1943). Maternología Profiláctica. Madrid: Editora Nacional.

Gallego Méndez, María Teresa (1983). Mujer, Falange y Franquismo. Madrid: Taurus.

Jiménez Lucena, Isabel (1997). «Medicina social, racismo y discurso de la desigualdad en el primer franquismo». En Ciencia y fascismo. Eds. Rafael Huertas y Carmen Ortiz. Madrid: Doce Calles. 111-126.

—y María José Ruiz Somavilla (2001). «Un espacio para mujeres. El Servicio de Divulgación y Asistencia Sanitario-Social en el primer franquismo». Historia Social 39: 67-85.

—, Ma José Ruiz Somavilla y Jesús Castellanos Guerrero (2002). «Un discurso sanitario para un proyecto político. La educación sanitaria en los medios de comunicación de masas durante el primer franquismo». Asclepio 54 (1): 201-218.

Martín Gaite, Carmen (1987). Usos amorosos de la posguerra española. Barcelona: Anagrama.

Nash, Mary (1996). «Pronatalismo y maternidad en la España franquista». En Maternidad y políticas de género: la mujer en los estados de bienestar europeos, 18801950. Eds. Gisela Bock y Pat Thane. Madrid: Cátedra. 279-308.

Palacio Lis, Irene (2003). Mujeres ignorantes: madres culpables. Adoctrinamiento y divulgación materno-infantil en la primera mitad del siglo XX. Valencia: Universitat de València.

Polo Blanco, Antonio (2006). Gobierno de las poblaciones en el primer franquismo (1939-1945). Cádiz: Servicio de Publicaciones de la Universidad de Cádiz.

Richmond, Kathleen (2004). Las mujeres en el fascismo español. La Sección Femenina de la Falange, 1934-1959. Madrid: Alianza Editorial. 
Ruiz Carnicer, Miguel Ángel (1996). El Sindicato Español Universitario (SEU), 1939-1965. La socialización política de la juventud universitaria en el franquismo. Madrid: Editorial Siglo Veintiuno.

Sánchez López, Rosario (2007). Entre la importancia y la irrelevancia. Sección Femenina: de la República a la Transición. Murcia: Editora Regional de Murcia.

Suárez Fernández, Luis (1992). Crónica de la Sección Femenina y su tiempo. Madrid: Asociación Nueva Andadura. 